\title{
"Yellow Trash"
}

\section{William Alexander Lesman \\ Fairfax, VA}

\section{B.A., Amherst College, 1995}

A Thesis Presented to the Graduate Faculty of the University of Virginia in Candidacy for the Degree of Master of Arts

\section{Department of English}

\section{University of Virginia} August 1996

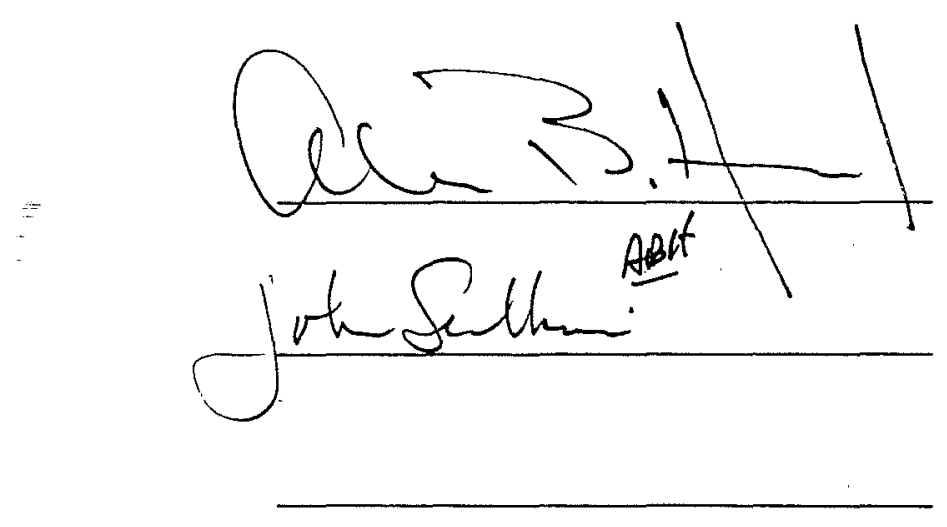




$$
\begin{aligned}
& \text { ALD } \\
& \text { Masters } \\
& \text { English } \\
& 1996 \\
& 147
\end{aligned}
$$

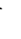


Note: This thesis is a hypertext. It may be found on the World-Wide Web at http://xroads.virginia.edu/ MA96/lesman

Abstract: The Fox cartoon situation comedy The Simpsons is in some respects typical of its genre, telling moral tales that affirm the nuclear family. But in other important ways, it is a distinctive product of the current television milieu and the postmodern condition. Like the vast majority of situation comedies, The Simpsons revolves around the family. It has been criticized for lacking traditional values, but in fact, beneath an irreverent surface, its characters do display mutual loyalty and affection. In the context of family sitcoms since the beginning of the television era, The Simpsons can be seen as upholding the traditional family structure (man as breadwinner, woman as housewife) dominant in 1950's programs, while incorporating many realistic issues and problems that were first broached in 1970's programs, including economic anxiety and moral confusion. Formally, The Simpsons takes advantage of its cartoon status to present itself in a fast-paced and eye-catching manner in order to hold the attention of viewers with short attention spans in a highly competitive home entertainment market. Further, it regularly employs self-reflexive techniques that reveal its artifice as a cartoon to the viewer, and it makes frequent allusions to "popular" and "high" culture. Together, these postmodern techniques function to "denaturalize" some of the dominant features of our way of life, especially the entertainment business. Nonetheless, The Simpsons like other postmodern texts, cannot avoid complicity in the very system it intends to undermine: while it criticizes contemporary American consumer capitalism, it is itself a highly successful consumer product. 